\title{
Bilateral Posterior Canal Benign Paroxysmal Positional Vertigo Co-existing with Cranial Nerves Schwannoma and Meniere Disease: Case Report
}

\section{Chua KWD ${ }^{1,2 *}$}

${ }^{1}$ Department of Otolaryngology, Changi General Hospital, Singapore

${ }^{2}$ The American Institute of Balance (AIB), USA

*Corresponding author: Kenneth Chua Wei De, Department of Otolaryngology, Changi General Hospital, Singapore, 529889, Tel: 6569365259; Email: Kenneth_chua@cgh.com.sg

\section{Case Report}

Volume 5 Issue 2

Received Date: September 24, 2020

Published Date: October 05, 2020

DOI: $10.23880 /$ ooaj-16000201

\section{Abstract}

Benign Paroxysmal Positional Vertigo (BPPV) is characterized by intense positional provoked vertigo with a brief duration and is one of the most common types of peripheral vestibular problems. The most commonly affected semi-circular canal is the posterior canal with a greater prevalence seen in females between the ages of 71-80. BPPV has a $60 \%$ right ear predisposition with canalithiasis as the predominant type. Most cases are unilateral, although bilateral BPPV is not atypical when associated with falls with head trauma, ototoxicity or co-existing vestibulopathy. To our knowledge, reports on bilateral BPPV coexisting with bilateral progressive vestibulopathy are scant. We describe a case of bilateral posterior canal BPPV with definite Menieres Disease (MD), Vestibular Schwannoma (VS) secondary to a schwannoma arising from the Jugular Foramen (JF) with mass effect and an incidental schwannoma of the right orbital optic nerve. Underlying BPPV may mask other clinical presentations, making it challenging to diagnose co-existing vesitbulopathy, especially those of a progressive episodic nature. In making management decisions, this serves as a reminder for clinicians to have in-depth conceptual and procedural knowledge to recognise and focus on the insidious progressive pathologies and not be distracted by the easily treatable BPPV.

Keywords: Benign paroxysmal positional vertigo; Vestibulopathy; Canial nerves schwannoma

Abbreviations: MD: Menieres Disease; VS: Vestibular Schwannoma; JF: Jugular Foramen; BPPV: Benign Paroxysmal Positional Vertigo; ED: Emergency Department; ENT: Ear-Nose-Throat; DHP: Dix-Hallpike; CRM: Canalith Repositioning Maneuver; URTI: Upper Respiratory Tract Infection; SNHL: Sensorineural Hearing Loss; ESR: Erythrocyte Sedimentation Rate; JF: Jugular Foramen; NES: Neuroscience; SRS: Stereotactic Radiosurgery; SLM: Semont Liberatory Maneuver.

\section{Introduction}

Benign Paroxysmal Positional Vertigo (BPPV) is one of the most common types of peripheral vestibular problems with a unilateral predisposition [1]. However, bilateral BPPV is not atypical when associated with head trauma, [2] falls, ototoxicity, or co-existing vestibulopathy [3]. To our knowledge, this is the first report of a bilateral posterior canal BPPV (with a cupulolithiasis variant) coexisting with bilateral vestibulopathy. The diagnosis and management of this patient was challenging and served as a reminder that clinicians need to recognise the possible co-existence of multiple neurotologic problems that may confound findings and delay diagnosis. A multi-disciplinary team may also be needed to provide holistic care and manage the patient's chronic functional impairments. 


\section{Otolaryngology Open Access Journal}

\section{Case Report}

A 67-year-old patient presented to our hospital on the 5th of May 2020, for the primary concern of vertigo and disequilibrium. The patient noted a complex medical history, with a 13-year history of episodic dizziness and imbalance. The patient remarked that these episodes were of a short duration, over a 3-4 weeks period in 2007. She notes having seen a neurologist and was unremarkable for any focal neurological deficits or specific signs. Aside from small chronic microvascular ischemic changes, radiographic imaging of the brain was negative for any acute infarct or intracranial haemorrhage. Giddiness was intermittent for the next few years, with two episodes of right eye erythema and blurring of vision in 2013, which was treated symptomatically by an Ophthalmologist. The patient also noted being asymptomatic in-between episodes of giddiness.

In September the following year (2014), the patient presented to the Emergency Department (ED) with complains of sudden onset of vertigo lasting minutes in duration and provoked by changes in vertical head-pitch. Bedside examination was unremarkable for any cerebellar or focal neurological signs and the patient received a prompt referral to the Ear-Nose-Throat (ENT) department.

Examination by the Otolaryngologist the following day was unremarkable for neurotologic signs. Audiometry and tympanometry were also unremarkable. However, as the patient noted that symptoms were worse with rightward head turns, Dix-Hallpike (DHP) was performed, with positive findings on the right. The patient was hence diagnosed with right posterior canalithiasis and treated with Canalith Repositioning Maneuver (CRM). After two followup appointments, the patient had complete resolution of symptoms and was hence, discharged from the outpatient ENT clinic in November the same year (2014). Three years later (2017), the patient returned to the ED for intense vertigo, which she remarked lasted hours in duration each time for a two-week period. Bedside head thrust was positive to the left and further supported by a positive Fukudastepping test. Because of the preceding upper respiratory tract infection (URTI), unremarkable audiometry and the reported duration of vertigo, the patient was diagnosed with a left vestibular neuronitis. DHP was deferred, as the patient was too symptomatically sick for the procedure to be carried out.

In February 2018, the patient reported a recurrence of vertigo. This time, she noted that symptomology lasted more than a few minutes, accompanied by aural fullness and tinnitus in the right ear. All bedside neurotologic examinations were unremarkable, except for a right low frequency Sensorineural Hearing Loss (SNHL). As this was the patient's first report of aural symptoms, she was diagnosed with probable Menieres Disease on the right. Laboratory workup (including an autoimmune, renal, and thyroid panel, full blood count) and radiographic imaging were ordered by the physician to rule out other causes of an asymmetrical SNHL.

Results were unremarkable except for a raised Erythrocyte Sedimentation Rate (ESR), which alone was insufficient to warrant a Rheumatology consult, and an incidental finding of a left Jugular Foramen (JF) schwannoma. Clinical findings were however negative for any neurologic signs. The patient was hence treated symptomatically with Betahistine and referred to the Neuroscience (NES) Center for further management.

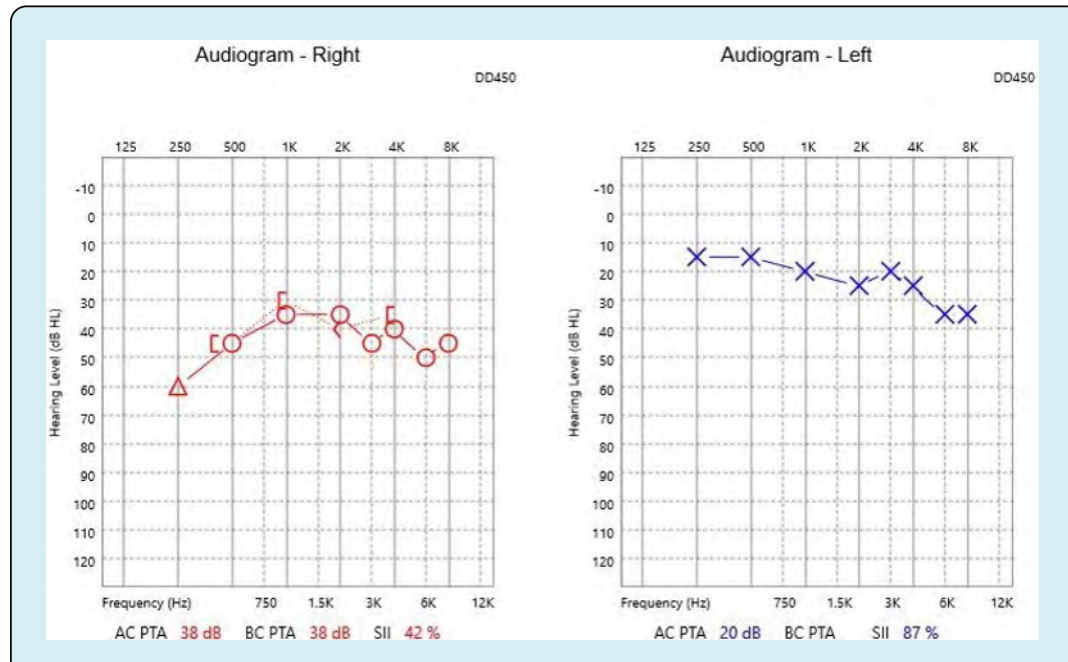

Figure 1: Audiogram of patient tested February 2018. 

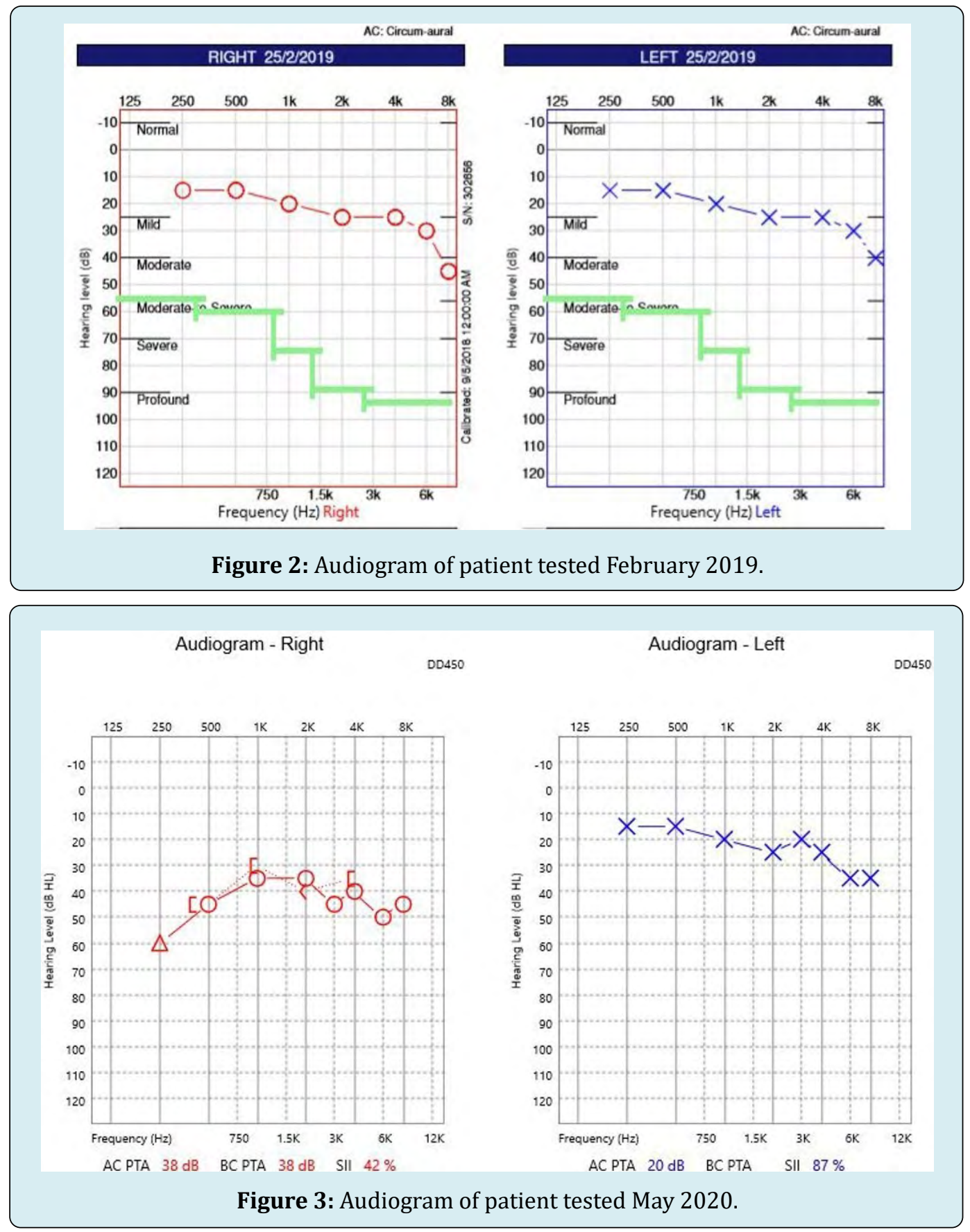

The patient noted that she was asymptomatic for the rest of 2018 but had undergone stereotactic radiosurgery (SRS) because her schwannoma had grown with a mass effect, pressing on the superior parts of the cochlea-vestibular nerves. Routine radiographic imaging in September 2018 after five rounds of SRS, showed a stable JF schwannoma with reduction in size, and incidental discovery of another schwannoma arising from the right orbital optic nerve. The patient was however free of vertigo and the audiogram returned to baseline, until she experienced a Menieres attack during her current admission this year (2020). As a low frequency SNHL was observed again in the right ear with periods of recovery in between attacks, this cemented her MD diagnosis on the right (Figures 1-3). DHP was positive for bilateral posterior canal BPPV, with classic canalithiasis on the left but no latency and longer duration on the right suggesting a cupulolithiasis variant.

Semont Liberatory Maneuver (SLM) was performed with good resolution on the left, but poor outcomes on the 
right despite four attempts. Post-treatment Hall-pike was still positive on the right despite Epley and Semont CRM. As headshaking was involved in the CRM, a momentary horizontal nystagmus was observed, which suggested a lateral canal involvement. However, this was not repeatable on the Pagnini-Mcclure supine roll test. Hence, considering the incomplete bilateral vestibulopathy, the horizontal nystagmus was likely from an asymmetrical velocity storage. Repeated DHP the following week was still positive for right posterior canal cupulolithiasis that appears to be resistant to repeated CRM. A summary of clinical findings can be found in Table 1. The patient was hence scheduled for a follow up appointment, to consider surgical canal plugging or intratympanic labyrinthine ablation with gentamicin, which may be able to help control both MD and BPPV. However, given that she has vestibular schwannoma on the left ear, she may not be able to effectively compensate after a unilateral labyrinthine ablation. Aside from pharmacological or surgical interventions, if the patient continues to experience vertigo due to intractable BPPV and active MD, she will need long-term vestibular rehabilitation.

\begin{tabular}{|c|c|c|c|c|c|}
\hline Year & $\begin{array}{c}\text { Duration of Giddiness/ } \\
\text { Vertigo }\end{array}$ & Procedure & Results & Remarks & Diagnosis \\
\hline 2007 & Minutes & Neurotologic Examination & Unremarkable & Neurology & N.A \\
\hline \multirow{5}{*}{2014} & \multirow{5}{*}{ Minutes } & Head thrust & Unremarkable & \multirow{5}{*}{ ENT } & \multirow{5}{*}{ Right PC-BPPV } \\
\hline & & $\begin{array}{l}\text { Cerebellar and Cranial } \\
\text { Nerves Examination }\end{array}$ & Unremarkable & & \\
\hline & & Dix Hall-Pike & $\begin{array}{c}\text { Positive } \\
\text { Positive to the right } \\
\text { asdasd }\end{array}$ & & \\
\hline & & Untenberger & Unremarkable & & \\
\hline & & Rhomberg & Unremarkable & & \\
\hline \multirow{5}{*}{2017} & \multirow{5}{*}{ Hours } & Head thrust & Positive to the left & \multirow{5}{*}{ ENT } & \multirow{5}{*}{$\begin{array}{l}\text { Left Vestibular } \\
\text { Neuronitis }\end{array}$} \\
\hline & & $\begin{array}{l}\text { Cerebellar and Cranial } \\
\text { Nerves Examination }\end{array}$ & Unremarkable & & \\
\hline & & Dix Hall-Pike & Unremarkable & & \\
\hline & & Untenberger & Positive to the left & & \\
\hline & & Rhomberg & Unremarkable & & \\
\hline \multirow{8}{*}{2018} & \multirow{8}{*}{$\begin{array}{l}\text { Minutes to Hours with } \\
\text { tinnitus and aural fullness }\end{array}$} & Audiometry & $\begin{array}{l}\text { Audiogram: Low } \\
\text { frequency SNHL on the } \\
\text { right }\end{array}$ & \multirow{8}{*}{ ENT } & $\begin{array}{l}\text { Right Probable } \\
\text { Menieres Disease }\end{array}$ \\
\hline & & $\begin{array}{c}\text { Radiographic imaging } \\
\text { of the internal auditory } \\
\text { meatus (IAM) }\end{array}$ & $\begin{array}{l}\text { Left Jugular Foramen (JF) } \\
\text { Schwannoma }\end{array}$ & & \multirow{7}{*}{$\begin{array}{c}\text { Left JF } \\
\text { Schwannoma }\end{array}$} \\
\hline & & Full blood count & $\begin{array}{l}\text { Raised Erythrocyte } \\
\text { Sedimentation Rate }\end{array}$ & & \\
\hline & & Untenberger & Unremarkable & & \\
\hline & & Rhomberg & Unsteady & & \\
\hline & & $\begin{array}{l}\text { Cerebellar and Cranial } \\
\text { Nerves Examination }\end{array}$ & Unremarkable & & \\
\hline & & $\begin{array}{l}\text { Head thrust, } \\
\text { Dix Hall-Pike }\end{array}$ & $\begin{array}{l}\text { Positive bialterally } \\
\text { Unremarkable }\end{array}$ & & \\
\hline & & $\begin{array}{l}\text { Autoimmune, Renal, } \\
\text { Thyroid panel }\end{array}$ & Unremarkable & & \\
\hline
\end{tabular}




\section{Otolaryngology Open Access Journal}

\begin{tabular}{|c|c|c|c|c|c|}
\hline \multirow{4}{*}{2018} & \multirow{4}{*}{ No vertigo } & $\begin{array}{c}\text { Stereotactic } \\
\text { Radiosurgery (SRS) }\end{array}$ & $\begin{array}{l}\text { JF schwannoma- mass } \\
\text { effect on cochlea- } \\
\text { vestibular nerves }\end{array}$ & \multirow{4}{*}{ NES/ENT } & $\begin{array}{l}\text { Left vestibular } \\
\text { Schwannoma } \\
\text { secondary to } \\
\text { mass effect. }\end{array}$ \\
\hline & & $\begin{array}{l}\text { Routine Radiographic } \\
\text { Imaging of the IAM and } \\
\text { brain }\end{array}$ & $\begin{array}{l}\text { Right orbital optic nerve } \\
\text { schwannoma }\end{array}$ & & \multirow{3}{*}{$\begin{array}{l}\text { Right orbital } \\
\text { optic nerve } \\
\text { schwannoma }\end{array}$} \\
\hline & & $\begin{array}{l}\text { Clinical neurotologic } \\
\text { examination }\end{array}$ & Unremarkable & & \\
\hline & & Audiometry & $\begin{array}{c}\text { Audiogram returned to } \\
\text { baseline }\end{array}$ & & \\
\hline \multirow{4}{*}{2019} & \multirow{4}{*}{ Minutes to Hours } & $\begin{array}{c}\text { Clinical neurotologic } \\
\text { examination }\end{array}$ & Unremarkable & \multirow{4}{*}{ ENT } & $\begin{array}{c}\text { Right Definite } \\
\text { Menieres Disease }\end{array}$ \\
\hline & & Audiometry & $\begin{array}{c}\text { Low frequency SNHL on } \\
\text { the right }\end{array}$ & & $\begin{array}{l}\text { Identified Left } \\
\text { Vestibular } \\
\text { Schwannoma }\end{array}$ \\
\hline & & Dix- Hallpike & Positive bilaterally & & \multirow[t]{2}{*}{ Bilateral BPPV } \\
\hline & & Head thrust & $\begin{array}{c}\text { Bilateral positive head } \\
\text { thrust }\end{array}$ & & \\
\hline
\end{tabular}

Table 1: Summary of Clinical Findings from 2007-2019.

\section{Discussion}

The management ofBPPV with co-existing vestibulopathy is not easy. Clinicians may be distracted by the quick and easy fix of BPPV when classic symptoms are presented, detracting from the slow insidious nature of progressive vestibular problems. Aside from the poorer outcomes of BPPV treatment, vestibulopathy predisposes one to recurring BPPV [4-7]. In addition, with a cupulolithiasis variant of BPPV, repeated CRM may be needed, with less success of a remission [8]. Surgical interventions may not be ideal in this case, considering a compromised vestibular function in the contralateral ear. Hence, long- term vestibular rehabilitation for MD and recurrent BPPV may be needed. This should involve a multidisciplinary team of clinicians with good procedural and conceptual knowledge whose focus is on managing the patient's functional impairments. It remains unknown if BPPV in this patient was secondary to bilateral vestibulopathy or a coincidental occurrence.

\section{Conclusion}

Vestibulopathy of an insidious and progressive nature like VS and MD are often hard to diagnose and may remain undetected for years. When presenting with co-existing $\mathrm{BPPV}$, it may be convenient and presumptuous to assume that BPPV is the only diagnosis. It is the "lowest hanging fruit" that is often easy to treat but does not preclude the individual from co-existing vestibulopathy. If BPPV is recurrent and intractable, treatment options may include surgical ablation or plugging of the labyrinth. However, as recent literature suggested the correlation between hypovitaminosis D and recurrent BPPV [9], clinicians should also assess serum vitamin D levels in BPPV patients and correct vitamin D levels to improve the prognosis of BPPV before considering surgical treatments.

\section{References}

1. Parham K, Kuchel GA (2016) A Geriatric Perspective on Benign Paroxysmal Positional Vertigo. J Am Geriatr Soc 64(2): 378-385.

2. Chua KWD, Gans RE, Spinks S (2020) Demographic and clinical characteristics of BPPV patients: a retrospective large cohort study of 1599 patients. J Otolaryngol ENT Res 12(1): 20-30.

3. Von Brevern M, Seelig T, Neuhauser M, Lempert T (2004) Benign Paroxysmal Positional Vertigo Predominantely Affects the Right Labyrinth. J Neurol Neurosurg Psychiatry 75(10): 1487-1488.

4. Parnes LS, McClure JA (1992) Free-floating endolymph particles: a new operative finding during posterior semicircular canal occlusion. Laryngoscope 102(9): 988-992.

5. Katsarkas A (1999) Benign Paroxysmal Positional 


\section{Otolaryngology Open Access Journal}

Vertigo (BPPV): idiopathic versus post-traumatic. Acta Otolaryngo 119(7): 745-749.

6. Stefano AD, Dispenza F, Suarez H, Fernandez NP, Huarte RM, et al. (2014) A multicenter observational study on the role of comorbidities in the recurrent episodes of benign paroxysmal positional vertigo. Auris Nasus Larynx 41(1): 31-36.

7. Tanimoto H, Doi K, Nishikawa T, Nibu KI (2008) Risk Factors for Recurrence of Benign Paroxysmal Positional
Vertigo. J Otolaryngol Head Neck Surg 37(6): 832-835.

8. Ruckenstein MJ (2001) Therapeutic Efficacy of the Epley Canalith Repositioning Maneuver. The Laryngoscope 111(6): 940-945.

9. Talaat HS, Kabel AMH, Khaliel LH, Abuhadied G, El Naga HAEA, et al. (2016) Reduction of Recurrence Rate of Benign Paroxysmal Positional Vertigo by Treatment of Severe Vitamin D Deficiency. Auris Nasus Larynx 43(3): 237-241. 